\title{
Negociación colectiva, acción sindical e intercambio político. Un planteamiento teórico apoyado en el análisis de las relaciones laborales en los astilleros de Cádiz
}

\author{
Sofía Pérez de Guzmán Padrón \\ Universidad de Cádiz. GEHA (Grupo de Estudios de Historia Actual) \\ sofia.perez@uca.es
}

\section{Resumen}

El concepto de intercambio político introducido por Alessandro Pizzorno en el campo de las ciencias sociales a finales de la década de 1970 ha sido ampliamente utilizado como marco analítico para abordar el tipo de intercambio mediante el cual tienen lugar los pactos de concertación social. Mucha menos atención ha sido prestada, sin embargo, a la capacidad explicativa de este concepto para analizar uno de los tipos de intercambio que, junto al intercambio individual y al de la negociación colectiva, se producen en el mercado de trabajo. El objeto de este artículo es, precisamente, profundizar en los rasgos y en los procesos que caracterizan al intercambio político y lo distinguen de las transacciones que tienen lugar en el mercado de la negociación colectiva en base a un caso concreto y singular: el de la acción sindical en una empresa pública, el astillero de Puerto Real (Cádiz). A partir del análisis de este caso, se propone un planteamiento teórico y una estrategia analítica aplicables a todos aquellos casos y circunstancias de relaciones laborales en los que la amenaza de cierre, deslocalización o despidos masivos en empresas — públicas o privadas - hace que entre o pueda entrar en juego una acción sindical marcada por la lógica del intercambio político.

Palabras clave: sindicatos; acción colectiva; conflictos laborales; construcción naval; Pizzorno, Alessandro.

Abstract: Collective bargaining, trade union action and political exchange. A theoretical approach supported by the analysis of labour relations in the shipyards of Cadiz, Spain

The concept of political exchange, which was introduced by Alessando Pizzorno in the social sciences at the end of the seventies, has been widely used as an analytical framework for addressing the kind of exchange by which social pacts take place. Nevertheless, much less attention has been paid to the explanatory capacity of this concept for analysing one type of exchange which, in addition to individual exchange and collective bargaining, takes place in the labour market: political exchange. The aim of this article is to examine in 
depth the features and processes that characterise political exchange and distinguish it from exchanges that take place in the collective bargaining market through the study of a particular case: collective action by trade unions in a public enterprise, the Puerto Real shipyard in Cadiz, Spain. Based on our analysis, we suggest a theoretical approach and an analytical strategy that can be applied to labour relation situations and circumstances in which the threat of closure, relocation or massive dismissals in public or private enterprises lead trade unions to resort to collective action characterised by the logic of political exchange.

Keywords: trade unions; collective action; labour disputes; shipbuilding; Pizzorno, Alessandro.

\section{Sumario}

\section{Introducción}

2. La singularidad de la empresa pública como contexto para la acción sindical

3. Estrategias laborales, negociación «triangular»e intercambio político implícito

4. Los recursos de poder de los sindicatos en el intercambio político
5. Algunos factores condicionantes del éxito del intercambio político

6. La capacidad explicativa del concepto de intercambio político más allá del ámbito específico de la empresa pública Referencias bibliográficas

\section{Introducción}

A finales de la década de 1970, Alessandro Pizzorno introdujo en las ciencias sociales el conocido concepto de intercambio político, que definió como un tipo de relación entre el Estado y las organizaciones sindicales en la cual «el poseedor de bienes (generalmente el Gobierno) está dispuesto a intercambiarlos por consenso social con otro actor que puede amenazar con destruir ese consenso (o, lo que es más o menos lo mismo, poner el orden en peligro), a menos que reciba los bienes que necesita» (Pizzorno, 1991: 384). Este concepto ha sido utilizado con profusión como marco analítico alternativo a los de concertación (Lehmbruch, 1977) y neocorporativismo (Schmitter, 1974) para abordar el tipo de intercambio - sistemático y a largo plazo- mediante el cual tienen lugar los pactos sociales, particularmente en aquellos casos en los que el Estado y las organizaciones sindicales desempeñan un papel central ${ }^{1}$. Es decir, para abordar el análisis de las situaciones, cada vez más frecuentes, en las que la relación entre sindicatos y empresas se ve sustituida por una «relación privilegiada entre sindicatos y Estado» (Miguélez, 1985: 150), cuyo principal objetivo es comprometer a estas organizaciones en el diseño y la puesta en práctica de determinadas políticas, entre las que destacan las de carácter económico y social.

1. Regini (1991, 1997 y 2000), quien defiende la superioridad del concepto de intercambio político frente a los de concertación y neocorporativismo, es uno de los autores que más ha aplicado este concepto al análisis de los pactos sociales. 
Mucha menos atención ha sido prestada, sin embargo, a la capacidad explicativa del intercambio político respecto a lo que el mismo Pizzorno (1991: 382) ha denominado los «aspectos políticos» del mercado laboral ${ }^{2}$. Este es, además, el sentido originario del concepto tal como fue expuesto por este autor en su ensayo Intercambio político e identidad colectiva en el conflicto laboral - publicado originalmente en 1978-, en el que caracteriza los tres tipos diferentes de intercambio que, desde su perspectiva, tienen lugar en el mercado laboral: el intercambio individual, el de la negociación colectiva y el intercambio político. Cada uno de estos tipos de intercambio tiene lugar en un contexto específico, cuya lógica de funcionamiento presenta características peculiares. El intercambio individual se produce, de acuerdo con Pizzorno (1991: 383), en el contexto del «mercado atomístico». En este mercado, el trabajador obtiene una retribución a cambio de trabajo, pero sus recursos de poder son muy limitados, dado que su única opción es dejar de trabajar en caso de que pueda hacerlo. Por el contrario, en el «mercado de la negociación colectiva», el trabajador está organizado en sindicatos y este hecho incrementa su poder de negociación, que en este caso proviene de su capacidad para interrumpir la continuidad del trabajo, lo cual origina un perjuicio económico a la empresa. El intercambio pasa a ser político - y a desarrollarse en el contexto del «mercado político»— cuando el interlocutor de los sindicatos es el Gobierno en lugar de la empresa y la amenaza es de destrucción del orden o del consenso social. Es evidente, por tanto, y así lo subraya Pizzorno (1991: 384), que el recurso en manos de los trabajadores en este último caso se regula de acuerdo con criterios completamente diferentes de los que rigen en el mercado de la negociación colectiva.

El objetivo de este artículo es, precisamente, profundizar en los rasgos y los procesos que caracterizan al intercambio político y lo distinguen de las transacciones que tienen lugar en el mercado de la negociación colectiva («situaciones contractuales» según las denomina Pizzorno), a partir del análisis de un caso concreto y singular: el de la acción sindical en una empresa pública, el astillero de Puerto Real (Cádiz) ${ }^{3}$.

El astillero de Puerto Real es una factoría naval especializada en la construcción de grandes buques que actualmente forma parte de la empresa pública Navantia ${ }^{4}$. Está situado en la Bahía de Cádiz, una comarca cuyo mercado local de trabajo se caracteriza por unas tasas de paro especialmente elevadas. Este astillero ha sido durante mucho tiempo la empresa más importante en términos

2. El único autor que ha aplicado este concepto de forma explícita al análisis de las relaciones laborales en el ámbito de la empresa ha sido Anthony Ferner (1990).

3. Expondremos aquí parte de los resultados de una investigación más amplia de carácter cualitativo sobre la acción sindical en la empresa pública centrada en el astillero de Puerto Real, cuyos límites temporales abarcan desde 1977 hasta la actualidad. Esta investigación ha sido presentada y defendida como tesis doctoral en la Universidad Complutense de Madrid.

4. La empresa pública Navantia se creó en marzo de 2005 como resultado de la segregación del área militar del antiguo grupo IZAR, que, a su vez, había surgido en diciembre de 2000 tras la fusión de los astilleros públicos civiles — la empresa Astilleros Españoles S.A. (AESA) - y los astilleros militares - la Empresa Nacional Bazan. Esta empresa cuenta con tres astilleros en la Bahía de Cádiz. 
de empleo de la zona, pero, desde finales de 1970, se ha visto afectado por la intensa crisis que viene sufriendo el sector naval. Como consecuencia de esta crisis y de las pérdidas económicas que ha generado, su plantilla ha sido sometida a cinco reconversiones (en 1977-1978, 1983-1984, 1995, 2000 y 2005) que han provocado importantes conflictos promovidos por los sindicatos.

El motivo de la elección de una empresa pública como caso objeto de estudio tiene mucho que ver con la singularidad de su lógica de funcionamiento y con los efectos de la misma sobre la acción sindical. La empresa pública desarrolla, igual que la privada, una actividad empresarial orientada al mercado, siendo la propiedad estatal el rasgo que establece la diferencia entre ambos tipos de empresa. Sin embargo, la diferencia entre las empresas públicas y las privadas no se agota en la cuestión de la titularidad, ya que la propiedad estatal da lugar, además, a ciertos rasgos peculiares 5 . Entre estos rasgos destacan, por una parte, el que las empresas públicas operen con frecuencia al margen del mercado y de la lógica del beneficio y, por otra, la constante injerencia de las autoridades políticas, que tienden a imponer sus directrices en los distintos ámbitos de gestión de estas empresas y, en especial, en el de las relaciones laborales. La consecuencia más inmediata de esta peculiar lógica de funcionamiento es que los sindicatos que actúan en las empresas públicas no sólo deben gestionar procesos de carácter estrictamente laboral — comunes a todas las empresas-, sino que también se ven obligados a enfrentarse continuamente a situaciones que requieren estrategias propias del mercado político, circunstancia que tiene el efecto de hacer especialmente evidentes los tipos de intercambio que nos proponemos analizar.

Así, al centrar nuestra investigación en la acción colectiva de los sindicatos en el astillero de Puerto Real, nuestro propósito no consiste simplemente en aportar al acerbo sociológico el análisis de las relaciones laborales en una empresa particular más, sino en tomarlo como observatorio privilegiado para el estudio de este tipo de procesos de intercambio en nuestro país, como un caso extremo representativo - una especie de ideal tipo- de todos aquellos casos y de todas aquellas circunstancias de relaciones laborales en los que la amenaza de cierre, deslocalización o despidos masivos en empresas - públicas o privadas - hace que entre o pueda entrar en juego una acción sindical marcada por la lógica del mercado político.

Desplegaremos los argumentos a favor de nuestras tesis de acuerdo con el siguiente orden expositivo. Comenzamos caracterizando el contexto en el que tiene lugar la acción colectiva de los sindicatos, esto es, la empresa pública. En segundo lugar, analizamos las diferencias entre la lógica que caracteriza a

5. Las peculiaridades de la lógica de funcionamiento de las empresas públicas ha sido analizada por numerosos investigadores procedentes, sobre todo, de los ámbitos de la economía y de la empresa. Entre ellos, destaca Cuervo (1985, 1986, 1992, 1997a y 1997b). También se ha abordado el análisis de estas empresas desde la sociología, centrándose, sobre todo, en el funcionamiento de las relaciones laborales en las mismas. Destacan, en este aspecto, las contribuciones de Batstone el al. (1984), Ferner (1985, 1986, 1987a, 1987b, 1990 y 1994) y Pendleton (1988, 1991a, 1991b, 1994, 1997a y 1997b). 
las transacciones que tienen lugar en el mercado de la negociación colectiva y la que particulariza al mercado político, basándonos en la observación del comportamiento estratégico de los sindicatos en dos tipos de situaciones: con ocasión de la negociación de las condiciones de trabajo y ante conflictos relacionados con la defensa del empleo. En tercer lugar, consideramos los factores que pueden condicionar el éxito de estas organizaciones en el intercambio político. Finalmente, a modo de conclusión, argumentamos la capacidad explicativa del concepto de intercambio político para analizar los procesos de conflicto y negociación más allá del ámbito de la empresa pública.

\section{La singularidad de la empresa pública como contexto para la acción sindical}

Como hemos señalado, la propiedad estatal convierte a las empresas en entidades económicas singulares: sus objetivos suelen ser de índole variada y diversa y, con frecuencia, el económico no es el principal. Además, su gestión se halla sujeta a presiones e injerencias políticas sistemáticas. Estas peculiaridades, presentes en diverso grado en todas las empresas públicas, constituyen un entorno singular al que deberá adaptarse la acción sindical hasta convertirla en un tipo de acción obligada a jugar en varios campos a un mismo tiempo.

En general, todas las empresas públicas se ven sometidas en alguna medida al control de su gestión por parte de los poderes públicos. Pero, en el caso del astillero de Puerto Real, esta fiscalización es especialmente acusada, ya que, al tratarse de una empresa económicamente deficitaria, su funcionamiento depende de las aportaciones económicas del Estado. En este contexto, para mantener el apoyo político y financiero del que depende la factoría, la dirección de la empresa se verá obligada a acatar las directrices que el Gobierno decida imponer. Las palabras de uno de los miembros del equipo directivo son una prueba clara de ello:

A nivel de recursos humanos, de política sindical o de políticas industriales, tenía que aceptar las directrices de Madrid, cosa que asimilé, entendía, porque al fin y al cabo estaban poniendo dinero, claro, es que esto nos estaba costando el dinero [...] Me echaban en cara la dependencia con Madrid, y yo siempre decía: «Mira, tío, el que está pagando ahora es Madrid, que aquí estamos perdiendo dinero y el que está soltando dinero es Madrid». (Directivo- 4$)^{6}$

La repetida alusión a Madrid que se observa en las palabras de este directivo al referirse a las instancias superiores de las que recibe directrices tiene, en el contexto de injerencia política en el que actúa el astillero, un significado muy distinto del que tendría en el caso de cualquier empresa privada con sede central en Madrid y con varios centros de producción. Para los directivos del

6. Este fragmento y los siguientes proceden, si no se especifica otra fuente, de entrevistas en profundidad realizadas a miembros del equipo directivo del astillero y a sindicalistas. 
astillero - $-\mathrm{y}$, como veremos más adelante, también para los sindicalistas-, Madrid representa algo más que el lugar donde se ubica la cúpula directiva de Navantia y donde, por tanto, se definen los objetivos estratégicos de la empresa: se trata también —y quizás antes— de una pieza más del entramado político del Gobierno. La percepción generalizada en el astillero es que, aunque las directrices suelen proceder de la cúpula directiva de la empresa, ésta actúa en gran medida como intermediaria en la transmisión de los objetivos y de los criterios provenientes de las altas instancias de la Administración:

Primero, empezando porque a la cúpula del astillero la nombra el partido que está de turno... y los que están ahí empiezan a nombrar subdirectores, los puestos de principal confianza. (Directivo-3)

Y estas cosas de las empresas públicas, de los «polisarios» como decía uno, de los políticos empresarios. Les llamaban "polisarios». Siempre que venían era gente que no sabía nada del negocio de los barcos [...] Querían inventar la rueda otra vez, y dale: «Y esto ¿por qué se hace así?». (Directivo-4)

La permanente imposición de directrices por parte de autoridades políticas ajenas a la empresa ha terminado socavando la autonomía de la dirección, situación que no sólo es reconocida y aceptada por sus miembros, sino que, además, es compartida por los sindicatos:

En la vida diaria, cotidiana, era problemático. Te voy a decir por qué. Un director de Recursos Humanos tiene su director en la factoría, pero tiene su jefe en Madrid, que le marca unas directrices. Entonces las directrices, a veces...A veces se es muy obediente a Madrid. (Directivo-3)

Los directores que están aquí, o los jefes de personal que están aquí obedecen directrices que vienen de arriba. (Sindicalista CAT-1)

[...] lo que pasa es que la teoría de que el director de aquí es un hijo de la gran puta, pero que en Madrid me van... El director de aquí hace lo que le dicen en Madrid, y antes de decirte sí o no, lo consulta en Madrid. (Sindicalista CCOO-2)

La acción colectiva de los sindicatos se desarrolla, por tanto, en un contexto cuya lógica de funcionamiento requiere conductas estratégicas singulares y, en todo caso, diferentes de las que estas organizaciones despliegan habitualmente en las empresas privadas. En el sector privado, el objetivo prioritario que impone una disciplina externa a las actividades de las empresas es la rentabilidad (Grant, 1996: 58). Esta es, además, la lógica que subyace bajo los intercambios que se producen en el "mercado de la negociación colectiva» (Pizzorno, 1991: 384), en el que el poder de negociación de los sindicatos emana de su capacidad para interrumpir la continuidad del trabajo, lo cual provoca un perjuicio económico a la empresa: 
El empresario quiere que tú le produzcas lo más posible y ganes lo menos posible para tener el máximo beneficio y punto. Y tú, en la medida en que tu organización de fuera te lo permita, pues le demuestras que, o me pagas esto o si no tus beneficios van a ser menos, porque con las consecuencias económicas de una huelga o de un conflicto vas a ganar menos. Dame más para que tú también ganes más, si no, si me das menos, vas a ganar menos. Es una correlación, es una..., es una dialéctica mucho más sencilla ¿̨no? (Sindicalista CCOO-2)

Tal como se desprende de las palabras de este sindicalista, en la empresa pública esta dialéctica se torna más compleja. La permanente intervención política en distintos ámbitos de la gestión del astillero y, en especial, en las relaciones laborales, convierte a las autoridades políticas en interlocutores potenciales de los sindicatos. El resultado es que estas organizaciones cuentan, en su acción cotidiana, con dos tipos de interlocutores, la dirección y las autoridades políticas, cuyas lógicas de actuación se rigen por criterios muy diferentes. La dirección debe actuar, por definición, según criterios "empresariales". $\mathrm{Su}$ responsabilidad consiste en la gestión eficiente de los recursos materiales y humanos del astillero con el objetivo de construir, dentro del plazo establecido, los buques que les han sido encargados. Debido a ello, y a pesar de que las frecuentes presiones que recibe la dirección del astillero desde el ámbito político tienden a desdibujar este objetivo, los intercambios entre la dirección y los sindicatos pueden encuadrarse dentro de la lógica de la empresa privada y, en consecuencia, analizarse en términos de lo que Pizzorno (1991: 384) denomina el «mercado de la negociación colectiva». Las autoridades políticas, por su parte, funcionan con una dialéctica más compleja, caracterizada por la persecución de una gran diversidad de objetivos y por las tensiones existentes entre la estrategia a largo plazo del Gobierno - la reestructuración de un determinado sector industrial en declive, por ejemplo-y las consideraciones políticas a corto plazo, como las consecuencias que la pérdida de empleos o el desorden público podrían tener sobre sus resultados en unas elecciones próximas (Ferner, 1990: 80). En este terreno, el intercambio pasa a ser político, y el poder de los sindicatos descansa sobre la amenaza de destruir el consenso o el orden social (Pizzorno, 1991: 384).

\section{Estrategias laborales, negociación «triangular»e intercambio político implícito}

El análisis de las relaciones laborales en el astillero a lo largo del periodo estudiado revela numerosas situaciones en las que se manifiesta la complejidad y las tensiones que, según acabamos de sostener, caracterizan habitualmente la acción sindical. Entre estas situaciones, cabe destacar, por su valor ilustrativo, el proceso de negociación de los convenios colectivos entre 1983 y 1995. Durante esos doce años, la negociación colectiva en AESA estuvo estructurada en dos niveles: los convenios de centro, que se negociaban en cada astillero, venían precedidos por acuerdos marco. Estos acuerdos, en cuya negociación se dis- 
cutían y se pactaban los aspectos más relevantes de las condiciones de trabajo, vinculaban a todas las factorías de la División de Construcción Naval del Instituto Nacional de Industria ${ }^{7}$. Las estrategias desarrolladas por los sindicatos para adaptar su acción a estos dos ámbitos de negociación interrelacionados, pero con lógicas de funcionamiento potencialmente distintas, hacen especialmente visibles los procesos que acabamos de describir.

Así, la negociación de los convenios de centro se desarrollaba en principio de acuerdo con la lógica de los intercambios del «mercado de la negociación colectiva» descrita por Pizzorno (1991: 384). El que los temas centrales de la negociación colectiva quedasen cerrados en los acuerdos marco generaba entre los sindicalistas la impresión, a la hora de negociar los convenios de centro, de que las instituciones de relaciones laborales del astillero podían funcionar con cierta autonomía, es decir, libres de interferencias políticas. Debido a ello, las estrategias de los sindicatos se orientaban hacia el ámbito laboral:

[...] cuando veíamos que la negociación estaba estancada y no había posibilidad de avanzar, se hacía una asamblea y a movilizarse. En aquel entonces se usaba mucho en la dirección, ir a la dirección. Y, bueno, se decía: mañana se reúne la comisión a las diez de la mañana. Pues mañana todo el personal allí a la puerta de la dirección, a presionar [...] Por los convenios, cortar el puente, no. El puente se empezó a cortar a raíz de las reconversiones. Hombre, porque, digamos, la decisión estaba arriba. Aquí, la decisión, en teoría estaba en los que estaban allí puestos por la empresa, el director, el jefe de personal... [...] Ahora, ellos consultaban con sus jefes. Ellos, cuando tenían dudas, «bueno, pues mañana contestamos», o "contestamos dentro de dos días, que tenemos que consultarlo con Madrid». Oye, pero ellos también tenían que tener la mano ancha para convencer a sus jefes de cómo estaba la situación, que lo más idóneo podía ser esto o lo otro..., porque el de Madrid no conoce el convenio de aquí. (Sindicalista CAT-1)

Aún así, las palabras de este sindicalista demuestran que esta autonomía era más aparente que real, puesto que el margen de maniobra de la dirección era escaso. Algunos de los directivos entrevistados confirman, asimismo, la constante injerencia de la alta dirección de AESA en la negociación de los convenios:

La dirección negociaba vía línea telefónica con Madrid. (Directivo-2)

En el convenio dábamos la cara, discutíamos, pero casi siempre iba marcado por Madrid. (Directivo-4)

7. En la negociación de los acuerdos marco, que se desarrollaba en las oficinas centrales del INI en Madrid, participaban los representantes de las federaciones del Metal de los sindicatos representativos a nivel de sector —UGT, CCOO y, en ocasiones, ELA, CIG y el CAT-, por una parte, y representantes de AESA y de la DCN, por otra. La categoría de las partes firmantes evidencia el carácter político de estos acuerdos. 
Estos fragmentos de entrevistas ponen, así, de manifiesto un aspecto singular del proceso de negociación de los convenios de centro en el astillero: además de las tradicionales negociaciones bilaterales entre la dirección y los sindicatos, aquella solía mantener simultáneamente contactos y negociaciones con la cúpula directiva de la empresa. El que la negociación trascendiese los límites de la factoría y del mecanismo formal de negociación debilitaba la posición negociadora de la dirección, ya que, por ello mismo, ésta dejaba de ser el único interlocutor posible de los sindicatos. Así, conscientes de que la postura de la empresa estaba condicionada, al menos parcialmente, por directrices políticas, ante cualquier escollo en la negociación con la dirección la acción sindical se diversificaba: junto a medidas de presión de carácter laboral dirigidas a la dirección del astillero, los sindicatos orientaban su acción hacia el terreno político, tratando de influir sobre ésta mediante negociaciones con las autoridades políticas. En estas estrategias tenía un papel relevante la estrecha relación existente entre los sindicatos mayoritarios del astillero - UGT y $\mathrm{CCOO}-\mathrm{y}$ sus federaciones y confederaciones: frente a cualquier problema en la negociación, solían solicitar a las instancias superiores de sus organizaciones que apoyasen sus demandas ejerciendo presiones sobre la alta dirección de la empresa o sobre la Administración. Es lo que Ferner (1990: 83) ha denominado una negociación «triangular», es decir, una negociación en la que cada una de las partes trata de forma bilateral con las otras dos.

Ante este tipo de negociaciones, la percepción de todos los miembros del equipo de dirección entrevistados es que los intereses electorales de los políticos siempre han tendido a imponerse sobre los criterios empresariales, lo que ha llevado a éstos a ceder, con demasiada frecuencia, a las presiones de los sindicatos:

¿Por qué no quieren ellos la privatización? Porque ellos pierden todo su poder. El poder que tienen aquí los sindicatos es que si no están de acuerdo con la empresa ellos van a su federación, y las federaciones van a los políticos porque al final AESA depende de la SEPI. [...] ¿Quiénes son los que mandan en la SEPI? Pues los políticos que están puestos por el Gobierno... tienen acceso directo a los que mandan a nuestro presidente [...] Entonces, cuando hay follón, el político de allí dice: «Quillo, no me alborotes el gallinero, déjame esto en paz que pierdo votos, empiezan a quemarme y al final voy a perder votos». Y esto es lo que no le interesa al político. Por eso es más fácil convencerlo que al empresario. Entonces, claro, de la Agencia, del INI, o de la SEPI se llama al presidente: "Quillo, me vas a arreglar este problema, a ver qué puedes hacer con ellos». Entonces, a ellos les es más fácil ir por la rama política que a través de la rama empresarial, porque al político le cuestan los votos pero no le cuesta tanto el dinero [...] Y esa es la complejidad de la empresa pública. (Directivo-1)

El Comité de Empresa, muchas veces, líderes sindicales de aquí, conectan con líderes sindicales de Madrid. $\mathrm{Y}$ entonces le atacan al director general en Madrid, o a directivos de Madrid a nivel de líderes sindicales de Madrid: «Oye, mira, que en la factoría de Puerto Real pues quieren hacer esto y lo de más allá», "¿Qué a mí se me va a levantar otra vez el puñetero astillero de Puerto 
Real? ¿Otra vez los del puente ${ }^{8}$ ?». Entonces ese de allí le dice al de abajo, al director de Recursos Humanos: "Da marcha patrás». Se ha perdido el norte por eso, por los condicionamientos políticos. (Directivo-3)

Tal como sugieren estas palabras, el poder de los sindicatos en la negociación a nivel de factoría se basaba, en última instancia, en su capacidad para producir desorden público, lo que constituye, como hemos señalado más arriba, la materia del intercambio político. Esto pone en evidencia cómo la lógica de funcionamiento de la empresa pública conduce a los sindicatos, en su acción cotidiana, a conjugar dos tipos de estrategia potencialmente contradictorios. Así, como hemos visto, la negociación de los convenios de centro era concebida por los sindicatos, al menos inicialmente, como un proceso estrictamente laboral, en el cual los intercambios debían responder a la lógica del «mercado de la negociación colectiva». Esta concepción se veía reflejada en el tipo de movilizaciones que solían llevar a cabo para presionar a la dirección: acciones de diverso tipo (paros laborales, concentraciones, bajo rendimiento, etc.) dirigidas a interrumpir la continuidad del trabajo. Pero cuando estas estrategias no daban el resultado buscado, esto es, modificar la postura de la dirección a favor de los sindicatos, el convencimiento de que dicha postura estaba determinada, en gran medida, por las directrices emanadas del ámbito político conducía a estas organizaciones a promover paralelamente negociaciones e intercambios de carácter político. El recurso a las autoridades políticas constituía así la última fase del proceso de negociación, por lo que, de alguna manera, los sindicatos recurrían a estas autoridades como «tribunal de apelación» (Batstone et al., 1984: 220) contra la dirección.

En general, en estos intercambios, los recursos en manos de los sindicatos eran, como hemos visto, su capacidad de movilización y su aptitud para obtener la solidaridad y el apoyo del conjunto de la población de la zona, es decir, su enorme habilidad para convertir un problema laboral en el astillero en un problema social que afectaba a toda la Bahía. Sin embargo, aunque, como veremos en el próximo epígrafe, los sindicatos del astillero han demostrado esta habilidad en todas y cada una de las reconversiones a las que ha sido sometida la empresa, jamás han recurrido a este tipo de estrategia durante el proceso de negociación colectiva. En este caso, la relación que se producía entre los sindicatos y las autoridades políticas podría considerarse, según lo hace Ferner (1990: 219), como un intercambio político de carácter implícito.

8. Este informante se refiere a un tipo de movilización utilizada con profusión por los trabajadores del astillero en los procesos de reconversión: el corte de la carretera nacional IV a la altura del Puente José León de Carranza, uno de los dos únicos accesos con que cuenta la ciudad de Cádiz. Esta acción se ve facilitada por el hecho de que la carretera que da acceso al puente discurre paralela a la factoría. El caos circulatorio que desencadena el corte de este puente, que puede dejar a Cádiz prácticamente incomunicada durante horas, provoca la inmediata intervención de la policía. Los enfrentamientos entre las fuerzas antidisturbios y los trabajadores siempre terminan convirtiendo lo que originalmente es una protesta laboral en un problema de orden público, lo que garantiza un eco informativo que no se alcanza con formas más moderadas de protesta. 
Los dirigentes sindicales eran conscientes de que, junto a su capacidad de movilización de los trabajadores, su principal recurso de poder en el intercambio político era la sensibilidad de la población gaditana hacia los problemas de los astilleros y su disposición a movilizarse en su defensa ${ }^{9}$, pero también lo eran de que podían perder este apoyo si sobreexplotaban su capacidad para provocar desorden público:

La gente siempre dice: «Al puente. Vámonos al puente por cualquier tontería o por cualquier cosa». Y los sindicatos hemos dicho: «Oye, cualquier tontería no es motivo, hay que medir». Entonces tú tienes que usar las armas dependiendo de cómo sea el problema, esto es una cosa que tenemos que reservar para problemas muy gordos, muy gordos, y no desgastarla ni utilizarla, ni que le den por culo a la gente y tal, porque es perjudicial. $\mathrm{Y}$ tenemos que ganar a la gente, y explicarles por qué hacemos esto, que ya sabemos son cosas..., pero es que nos quieren despedir o quieren... Nosotros hemos procurado siempre matizar el tipo de problema y el tipo de respuesta, claro. (Sindicalista CCOO-2)

En definitiva, el análisis del comportamiento estratégico de los sindicatos durante la negociación de los convenios de centro nos permite observar las diferencias existentes entre la lógica que caracteriza a las transacciones que se producen en el mercado de la negociación colectiva y la que particulariza al intercambio político. Así, hemos observado que, en la medida en que las negociaciones con la dirección se refieren a cuestiones estrictamente laborales y productivas y, debido a ello, se encuadran en la lógica del mercado de la negociación colectiva, las movilizaciones organizadas por los sindicatos para ejercer presión son las tradicionales de carácter laboral. Pero el hecho de que, en las empresas públicas, el objetivo de la rentabilidad tienda a situarse en un segundo plano, unido a la posibilidad — siempre presente- de recurrir a las autoridades políticas ante cualquier contratiempo, hace que la fuerza de los sindicatos en estas negociaciones provenga, en última instancia, de su capacidad potencial - que nunca llegan a poner en práctica en estos casos, porque corren el riesgo de que pierda su eficacia- para producir desorden público, lo que es materia de intercambio político. Este tipo de procesos, que coloca a los sindicatos de las empresas públicas en el centro de una tensión permanente entre dos ámbitos de actuación, en el del mercado político y en el de la negociación colectiva clásica, muestra que cada uno de estos ámbitos funciona con su lógica particular y requiere su propia estrategia.

9. Dada la tradición que tiene la industria naval en la Bahía (el origen del astillero se remonta a 1891), los gaditanos siempre han asumido como uno de sus rasgos identitarios fundamentales su vínculo afectivo con los astilleros. Relacionan esta actividad con la prosperidad económica de la zona y la consideran como uno de los principales atributos de su historia y de su cultura. Esta representación de los astilleros, unida a una memoria histórica de sentimiento de abandono por parte del Gobierno, se traduce en la práctica en una especial sensibilidad hacia los problemas de los trabajadores del astillero y en una total disposición a movilizarse en su defensa. 


\section{Los recursos de poder de los sindicatos en el intercambio político}

Tal como acabamos de exponer, la tensión entre estrategias de intercambio político y estrategias estrictamente laborales es frecuente en los conflictos y en las negociaciones que tienen por objeto las condiciones de trabajo. Pero los sindicatos han debido enfrentarse, además, a numerosas situaciones que han supuesto amenazas reales o potenciales al mantenimiento del empleo en el astillero, entre las que destacan las cinco reconversiones a las que se ha visto sometida la plantilla. En estos casos, estas organizaciones han optado por situar el conflicto inequívocamente en el mercado político. Los sindicatos del astillero han mostrado siempre una gran habilidad para desenvolverse en este mercado, en el que cuentan con valiosos recursos de poder, entre los que destaca la sensibilidad de la población de la Bahía de Cádiz hacia los problemas de los astilleros y su disposición a movilizarse en su defensa.

Ya desde la reconversión de 1977-1978 - la primera que tuvieron que afrontar-, los sindicatos utilizaron la importancia económica y simbólica que tienen los astilleros para los gaditanos en favor de sus intereses, presentando la crisis de las factorías navales como una amenaza colectiva proveniente del exterior. En esta primera ocasión, los sindicatos, que veían venir la reconversión, se adelantaron al anuncio de la misma por parte de la empresa. Concretamente, llevaban meses desarrollando acciones que tenían como objetivo fomentar, entre la población de toda la Bahía, la percepción de la crisis de las factorías navales como un problema que afectaba a toda la comunidad y no sólo a los trabajadores de las mismas. Esta opción estratégica no surgió por casualidad, sino que, por el contrario, se basaba en un conocimiento previo de la relevancia que tenían los astilleros para la población de la zona, tal como revelan las entrevistas realizadas a algunos de los dirigentes sindicales del astillero que protagonizaron esta reconversión:

Resulta que ya la Bahía de Cádiz estaba obsesionada con que su salvación somos los astilleros desde principios de siglo. Desde principios de siglo ya ha habido manifestaciones, ya ha habido exigencias al Gobierno. Aquí, en la Bahía de Cádiz, hay muchas empresas públicas, no por casualidad, entre otras cosas porque ha habido una presión social ¿̨Por qué? Porque Cádiz no tiene salidas [...] ¿De qué van a vivir? Del muelle y de la empresa pública [...] Es que hay mucha gente que ha comido de los astilleros, mucha gente, para una ciudad tan pequeña como Cádiz [...] Entonces simbólicamente esto ha sido una cosa vital para la Bahía de Cádiz, y lo sigue siendo ¿̇no?, y lo sigue siendo. (Sindicalista CCOO-1)

Conscientes, por tanto, de que su principal recurso frente a la Administración era su capacidad para movilizar, en apoyo de sus reivindicaciones, a una población cuya economía dependía en gran medida de los astilleros y que, además, les atribuía una considerable relevancia simbólica, los sindicatos desarrollaron, durante los meses previos al anuncio de la crisis, una campaña de información sobre las posibles repercusiones de una reconversión o del cierre de los astilleros sobre la economía y el empleo de toda la comarca, cuyo 
objetivo era tratar de recabar el apoyo de la población y de las principales instituciones sociales y políticas de la zona. Esta labor se concretó, por una parte, en la difusión de comunicados dirigidos a la opinión pública en los que se enfatizaba la dependencia económica de la zona respecto a la construcción naval: «[...] la economía de la Bahía de Cádiz se apoya fundamentalmente en la construcción naval, y la construcción naval atraviesa la crisis más grave de su historia. El problema del desempleo podría adquirir, a medio plazo, perfiles dramáticos si no se toman medidas urgentes y profundas que resuelvan los problemas planteados» ${ }^{10}$. Y, por otra, en la búsqueda de la implicación del movimiento asociativo local, con objeto de obtener su apoyo a nivel institucional y de fomentar entre sus bases un movimiento social de oposición. Para ello realizaron numerosas reuniones informativas en asociaciones de vecinos y de comerciantes, en partidos políticos e instituciones locales:

Entonces estábamos todo el mundo pues eso, con un spray, bueno spray no teníamos, con brochas, con papeles, las máquinas multicopistas, entonces nos reunimos entre todo lo que son los astilleros primero, fuimos extendiendo, creamos reuniones en barrios [...], íbamos por barrios tanto en Cádiz, yo he ido muchísimas veces a Loreto, a Santa María [...] Sí, sí, a pedirles ayuda, y solidaridad para esa garantía de lucha y de huelga. Bueno, fue impresionante, entonces eso se trabajó, como hay que trabajar las cosas, entonces hay, hay digamos una credibilidad importante en la gente, en todo, y en los dirigentes de base, llamémosle a esta gente de base, ¿̇no? [...] teníamos reuniones ya en Cádiz, donde sindicatos, partidos, todos a una, empezamos a preparar el terreno para una gran manifestación en Cádiz, que hubo más de cien mil personas, la que te comenté antes, que eso está. Y eso antes se preparó con meses de antelación, es decir, que ya en Puerto Real nosotros hicimos nuestras propias manifestaciones, la plaza Jesús llenita, tenemos fotos ahí, pero empetá de gente, todo el pueblo [...] básicamente fueron eso, la lucha contra esa reconversión incipiente que unificamos a toda la Bahía de Cádiz de forma tremenda pero la preparamos con meses de antelación, con participación, con debates en barriadas, las mujeres organizadas creando también su propia lucha, la gente joven en el Porvenir [...] y había vallas, pequeñas manifestaciones que nos reuníamos allí en la plaza de Jesús, allí en la plaza antigua del Ayuntamiento. (Sindicalista CNT-1)

La experiencia de esta primera reconversión, que se saldó de manera muy positiva para los trabajadores, mostró a los sindicatos la importancia de extender los conflictos buscando el apoyo de la población para convertirlos en problemas políticos. De hecho, este mismo argumento ha sido utilizado en las reconversiones sucesivas que han tenido que afrontar, tal como refleja el siguiente fragmento:

[...] estábamos viendo las orejas al lobo. Entonces, pues, decidimos empezar el proceso como lo habíamos empezado en las reconversiones anteriores. Es decir,

10. Comunicado de los trabajadores del astillero de Puerto Real a la opinión pública (14 de abril de 1977). 
en nuestra lógica, primero había que cargarnos de argumentos [...] El diseño nuestro era, primero, cargarnos de razones. Es decir, sacar a la opinión pública y entrevistarnos con ayuntamientos, con Diputación, con agentes sociales, con asociaciones de vecinos, etc. Gracias a eso conseguimos una manifestación con cien mil personas en la primera reconversión en Cádiz. Es decir, primero informamos. Notas a la prensa, reunión con el alcalde o la alcaldesa de Cádiz. Todo eso publicitado. Asociación de vecinos, APAs, etc. Un mes y medio o dos meses explicando: «Tenemos este problema, necesitamos solidaridad pronúnciese a favor nuestro». Y después empezamos a apretar las clavijas. Una vez se ha informado y tal, el Gobierno no responde o no se han satisfecho nuestras expectativas, entonces hay que apretar las clavijas ${ }^{11}$.

Sin embargo, aunque la implicación y el apoyo generalizado proporcionados por los vecinos de la Bahía de Cádiz han sido factores cruciales y necesarios para el éxito de las estrategias de intercambio político de los sindicatos ${ }^{12}$, por sí solos no han servido para inclinar la balanza a favor de los trabajadores durante la negociación de los procesos de reconversión. El análisis de la evolución de estos procesos muestra que, una vez iniciados los conflictos, ni las movilizaciones de carácter pacífico, ni el fuerte respaldo de la población expresado mediante su masiva participación en las manifestaciones convocadas por los sindicatos, han servido para desbloquear los mismos. La intervención de las autoridades políticas, que habitualmente ha supuesto la resolución de los conflictos en unos términos relativamente favorables a los trabajadores, sólo se ha producido tras episodios - más o menos prolongados- de violencia callejera ${ }^{13}$ y ante la proximidad de unas elecciones o el inicio de una campaña electoral:

11. Fragmento de entrevista a un miembro del Comité de Empresa recogido en Florido et al. (2009: 84).

12. Investigaciones como las de Alas-Pumariño (1993) sobre la reestructuración industrial en Reinosa o la de Vega (1996) referida a la crisis industrial en Gijón han puesto de manifiesto que es imposible sostener este tipo de estrategias en un clima de incomprensión y aislamiento.

13. Los siguientes fragmentos publicados en la prensa y referidos a diferentes conflictos dan idea de la extrema violencia que termina caracterizando a las movilizaciones de los trabajadores del astillero: «Árboles arrancados de cuajo, barricadas en llamas, y los autobuses urbanos que fueron retirados del servicio ante los continuos asaltos eran las notas que describían la situación [...] la policía usó un variado arsenal de botes de humo y bolas de goma, mientras que desde los balcones eran arrojados sobre la policía un frigorífico, una máquina de coser, innumerables macetas, tuercas y tornillos» (El Pais, 27 de octubre de 1977); «59 personas resultaron heridas, tres de ellas de consideración, y otras dos detenidas durante las más de 13 horas de disturbios ocurridos ayer en Puerto Real, al término de una asamblea convocada por el comité de empresa y secciones sindicales de AESA de Matagorda. Grupos de trabajadores cortaron la carretera nacional IV Madrid-Cádiz en el Cartabón y en la circunvalación, la vía férrea, y atentaron contra dos arquetas de la Compañía Telefónica. Farolas derribadas, una decena de coches volcados, señales de tráfico arrancadas, una cabina de teléfonos destrozada y decenas de barricadas incendiadas, completan el balance de lo que ha sido la jornada más violenta de acciones de protesta protagonizada por los trabajadores de Astilleros Españoles de Puerto Real» (Diario de Cádiz, 28 de mayo de 1987). 
[...] yo creo que aquí a nosotros nos han valido los extremos, o sea, convertir el tema en una guerra, en una guerra. Lo hemos diseñado así como problema de orden público, follones y tal. Eso lo hemos ido combinando con movilizaciones de masas. Eso pasa por empezar a comprometer a ayuntamientos, sean del color político que sean, y utilizar los momentos electorales. Como todos los años tenemos elecciones por una cosa o por otra, pues...Y después, asociaciones de vecinos, claro, trabajan en astilleros pero después son el presidente de la peña de no sé donde, y de la asociación de padres de alumnos, y de... Entonces, aglutinar gente, aglutinar gente, aglutinar gente para movida de masas, hasta que el político descubra que llevar al último extremo sus pretensiones le va a costar un problema de orden público [... Y Ya te digo, un problema social y una rentabilidad electoral muy fuerte, esos son los trámites con los que nosotros intentamos jugar. (Sindicalista CCOO-1)

Esta misma interpretación es la que realizan los medios de comunicación. Como ejemplo, podemos citar algunos fragmentos publicados en periódicos ajenos a la Bahía de Cádiz que se refieren a la reconversión de 1995. Así, de acuerdo con un editorial del periódico Cinco Días: «El Ministro de Industria está en Japón. Se ha ido con la tranquilidad de que el plan para la reestructuración de los astilleros públicos está en marcha. No ha conseguido su plan inicial, se supone que bien pensado e incluso repasado en Consejo de Ministros, pero tuvo el reflejo de aceptar el de los comités de empresa de los astilleros argumentado de forma contundente por las calles de Cádiz» ${ }^{14}$. Y la perspectiva del diario La Vanguardia era muy similar: «Antes del verano hubo en Cádiz una tranquila manifestación de apoyo a sus astilleros que reunió a unas cien mil personas. No mereció ni unos segundos en los telediarios. Eso sí, bastó que un reducido grupo de exaltados provocara grandes disturbios para que Cádiz ocupara las portadas de todos los informativos y, lo que es más elocuente, que el Ministro de Industria corriera a buscar una solución negociada ${ }^{15}$.

En definitiva, como ha quedado demostrado, el poder de negociación de los sindicatos de los astilleros gaditanos se basa en su capacidad para obtener el apoyo de la población y para producir desorden público o, lo que es lo mismo, en su habilidad para situar el conflicto en el terreno de la política. A este respecto, tal como ha observado asimismo Vega (1996: 389) en el caso de la crisis industrial de Gijón, la postura adoptada sistemáticamente por las autoridades políticas ha terminado por volverse en su contra. Así, ante este tipo de movilizaciones, su reacción ha tendido a ser de expectación seguida, casi de inmediato, de acciones represivas tendentes a convertir los conflictos en cuestiones de orden público, para terminar cediendo cuando la presión social se intensifica en exceso o ante la inminencia de un proceso electoral. Esta actitud de las autoridades políticas no sólo refuerza la tendencia sindical a recurrir a este tipo de estrategia; también convierte las circunstancias políticas

14. Editorial, Cinco Días, 9 de octubre 1995.

15. La Vanguardia, 24 de septiembre de 1995. 
de cada momento en valiosas armas en manos de las organizaciones sindicales en el intercambio político.

De hecho, la habilidad que han mostrado los sindicatos, una y otra vez, para aprovechar las circunstancias políticas y los momentos electorales en su beneficio constituye una manifestación más de su destreza en el manejo de las claves del intercambio político. En este sentido, a pesar de que las luchas de los trabajadores no han logrado nunca bloquear las reconversiones, sí han conseguido evitar el cierre de una factoría que lleva más de treinta años con pérdidas, reducir el número de excedentes de plantilla y mejorar considerablemente las condiciones económicas de los trabajadores afectados por las mismas.

\section{Algunos factores condicionantes del éxito del intercambio político}

No obstante, para los sindicatos, el intercambio político también conlleva costes. La dificultad de encontrar un punto de equilibrio entre los compromisos que se adquieren en la esfera política y las demandas inmediatas de los trabajadores puede dar lugar a una brecha entre los intereses de los representados y los de los representantes que, si se agranda, puede provocar lo que Regini (1981: 54) ha calificado como «crisis de representación». Este riesgo se ve incrementado, según Ferner (1990) y Batstone et al. (1984), si existe competencia entre organizaciones sindicales dentro de una empresa. El análisis de la acción sindical en el astillero nos ha permitido observar de un modo directo los condicionamientos y las dificultades a los que deben hacer frente los sindicatos que participan en relaciones de intercambio político cuando lo hacen en el marco de un panorama sindical variado y complejo.

En este centro productivo coexisten cuatro organizaciones sindicales que se agrupan, en la práctica, en dos bloques con objetivos y criterios de actuación muy diferentes: de una parte, los tres sindicatos con presencia en el Comité de Empresa, Comisiones Obreras (CCOO), la Unión General de Trabajadores (UGT) y el Colectivo Autónomo de Trabajadores (CAT) y, de otra, la Confederación Nacional del Trabajo (CNT), un sindicato con pocos afiliados y sin representantes - por decisión propia - en dicho Comité y que, sin embargo, posee una extraordinaria capacidad para controlar la gestión del mismo y para obtener el respaldo de los trabajadores. La presencia en el astillero de este último sindicato no sólo provoca una constante tensión entre dos maneras distintas - y a veces contrapuestas - de entender la representación y la defensa de los intereses de los trabajadores, sino que, además, y sobre todo, limita la capacidad de representación unitaria por parte del Comité de Empresa. Esta situación se manifiesta, mayormente, en la constante objeción a las acciones y a las estrategias desarrolladas conjuntamente por los sindicatos mayoritarios por parte de la CNT:

[...] había un frente que era el Comité de Empresa compuesto por CCOO, UGT y el CAT, y otro frente que era CNT, que, como estaba en contra de 
los comités de empresa, pues prácticamente cualquier cosa que planteaba el Comité, cosa que CNT rechazaba. (Sindicalista CAT-1)

La CNT no estaba en la mesa de negociación, y desde fuera todo lo que firmáramos era malo, todo lo que pidiéramos era poco, cualquier acuerdo con el empresario es malo porque siempre se podía haber sacado más. (Sindicalista CCOO-2)

El clima de tensión entre los sindicatos mayoritarios y la CNT se ve agravado por la capacidad que muestra esta última organización para obtener el apoyo de los trabajadores en las asambleas. La negativa del sindicato anarquista de participar en las elecciones sindicales les lleva a organizar su acción en torno a las asambleas. Las asambleas, de asistencia masiva, no sólo constituyen la forma de implicación sindical más extendida entre los trabajadores, sino también, y sobre todo, el espacio donde se toman todas las decisiones importantes que afectan al colectivo. En ellas, la CNT adquiere un fuerte protagonismo, que viene a compensar su escasa intervención en las negociaciones o en las decisiones del Comité de Empresa, así como la baja afiliación con la que cuenta. Precisamente esta faceta de la CNT es destacada por Pedro Castilla, miembro de la dirección prejubilado, en su libro sobre el astillero de Puerto Real: «A los militantes de CNT el colectivo les veía como muy radicales en sus planteamientos, a pesar de que algunos de sus líderes fueran ejemplos de coherencia sindical, razón por la que gozaban de muy pocos afiliados. Sin embargo, son los que se llevaban, por su estrategia y propuestas, en las asambleas (era su terreno) el gato al agua» (2007: 129).

La participación de este sindicato en las asambleas supone, así, un permanente cuestionamiento de las posiciones y de las propuestas presentadas por las organizaciones mayoritarias y la posibilidad cierta de que los trabajadores terminen votando en contra de las mismas. En muchos casos, estas propuestas responden a las líneas estratégicas generales de negociación de sus respectivas federaciones, o a compromisos adquiridos por éstas en la esfera política y, por tanto, las intervenciones de la CNT ponen en peligro la capacidad de los sindicatos mayoritarios para comprometerse en relaciones de intercambio político a medio o a largo plazo. Al desposeer a los sindicatos mayoritarios del control sobre su base social, este sindicato puede llegar a comprometer la capacidad del Comité de Empresa para garantizar el cumplimiento en la factoría de lo que ha sido acordado en las negociaciones de alto nivel y, por tanto, su credibilidad en los tratos políticos. Igualmente, como se ha hecho evidente en este caso, puede crear las condiciones para que la natural laguna de interpretación que surge entre los sindicatos que participan en relaciones de intercambio político y su base social termine derivando en una crisis de representación ${ }^{16}$.

16. En el periodo analizado, encontramos numerosos casos en los que la CNT ha conseguido ganar votaciones en las asambleas con propuestas enfrentadas a las presentadas por el Comité de Empresa, o poner a la plantilla en contra de este órgano de representación, argumentando, por ejemplo, que actúa más guiado por las directrices y los compromisos políticos de los 
Sin embargo, y paradójicamente, el papel de la CNT en el desarrollo de las relaciones de intercambio político no siempre resulta perjudicial para los objetivos del Comité de Empresa. Cuando se producen situaciones excepcionales - como son los procesos de reconversión- este sindicato, en contraste con los planteamientos de las organizaciones cuya participación en relaciones de intercambio político les exige moderación, tiende a adoptar $-\mathrm{y}$ a promover - posturas radicales. Su capacidad y disposición para radicalizar la acción colectiva, que conlleva la organización de formas de protesta contundentes (incluso violentas) constituye un apoyo fundamental para los sindicatos mayoritarios en sus negociaciones con las autoridades políticas. En este aspecto, hemos observado cómo, de hecho, el afán de las autoridades políticas por evitar la violencia callejera y el consiguiente desorden público que conllevan las movilizaciones promovidas por la CNT — que se va incrementando a medida que se acerca un proceso electoral — ha tenido el efecto de reforzar la posición negociadora del Comité de Empresa en sus tratos con estas autoridades, tanto directamente en el caso de los conflictos provocados por procesos de reconversión como de manera indirecta ante los problemas que surgen en el día a día de la acción sindical:

Hombre, a nosotros nos venía un poco bien. Porque nosotros, quizás los tres, pecábamos un poco de, no sé si decir sensatos. No nos gustaba, nos daba miedo la guerrilla y a ellos les gustaba organizar la guerrilla ${ }^{17}$.

Mi experiencia como sindicalista es que los argumentos en la negociación... valen relativamente. Tú puedes llevar más razón que un santo, pero si tú no tienes una fuerza, si no tienes gente detrás y tal, pues te dirán: «Sí, tienes razón, pero esto es lo que hay» [...] Para que te la den tú tienes que arrimar algo más que argumentos. Ahora, argumentos tienes que tener, lógicamente. (Sindicalista CCOO-1)

Sin embargo, tal como refleja este último fragmento, la violencia promovida por la CNT es un factor necesario, pero no suficiente para la resolución de los conflictos. De hecho, las negociaciones con las autoridades políticas no

órganos federales de los sindicatos mayoritarios que movido por la defensa de los intereses de los trabajadores: «[...] las decisiones que toman los miembros del Comité en AESA vienen dictadas por los responsables de los sindicatos en Madrid, con lo que los trabajadores no tenemos ni arte ni parte en las negociaciones. Pretenden que asumamos las decisiones de gente que no entiende la situación porque no la viven, con lo que no estamos conformes» (reproducción de un fragmento de un comunicado de la Sección Sindical de la CNT en el diario El Periódico, 12 de abril de 1991). Ha habido, además, al menos dos ocasiones en las que el sindicato anarquista ha promovido movilizaciones al margen del Comité de Empresa que han sido secundadas masivamente por los trabajadores, lo que ha terminado provocando la dimisión de los miembros de este órgano de representación.

17. Fragmento de entrevista realizada a un miembro del Comité de Empresa, perteneciente a CCOO, recogido en Florido et al. (2009: 130). 
hubieran sido posibles sin la intervención del Comité de Empresa, no sólo porque constituye el único órgano legitimado para negociar y, por tanto, reconocido como interlocutor por la empresa, sino también porque, durante los conflictos, ha mantenido siempre una actitud abierta al acuerdo. En otras palabras, las acciones violentas e incontroladas enmarcadas en una estrategia sindical como la de la CNT nunca habrían reportado soluciones positivas sin la existencia de un órgano representativo dispuesto a encauzarlas y pactar. En definitiva, la resolución de los conflictos - y, por tanto, el éxito del intercambio político - ha sido posible gracias a una eficaz combinación entre la estrategia de movilización radical de la CNT y la capacidad y la disposición del Comité para reconducir la situación mediante una negociación basada en objetivos alcanzables.

\section{La capacidad explicativa del concepto de intercambio político más allá del ámbito específico de la empresa pública}

El estudio del caso del astillero de Puerto Real ha mostrado la capacidad explicativa del concepto de intercambio político para analizar los procesos de conflicto y negociación que tienen lugar en el complejo ámbito de la empresa pública. Pero, como señalamos en la introducción, el resultado de esta investigación va más allá de constituir una mera aportación al conocimiento sociológico de las características de la acción sindical en estas empresas.

El recurso a estrategias de intercambio político no es privativo de los sindicatos de las empresas públicas. Como han advertido Crouch (1982: 104) y Pizzorno (1991: 384), los sindicatos del sector privado pueden recurrir a este tipo de intercambio cuando sus representados se hallan en situaciones extremas (aunque no infrecuentes), como pueden ser el anuncio del cierre o deslocalización, o de despidos masivos en una empresa determinada. En esos casos, las estrategias laborales orientadas a presionar económicamente a la empresa pierden todo su sentido, ya que, como ha señalado Pizzorno (1991: 384), «el poder de mercado de los trabajadores pasa a ser nulo por definición, al no haber ninguna demanda de sus servicios». En consecuencia, los sindicatos tienden a recurrir a estrategias dirigidas a presionar al Gobierno para que intervenga en el conflicto, es decir, a estrategias políticas.

También en nuestro país se han dado actuaciones sindicales de este tipo. Es lo que observamos en las prácticas y estrategias desarrolladas por los sindicatos de empresas privadas como, por citar algunos ejemplos, los de Santana Motor (Linares, Jaén) en 1994, Samsung (Palau-solità i Plegamans, Barcelona) en 2004 o Delphi Automotive Systems (Puerto Real, Cádiz) en 2007, cuando se enfrentaron al posible cierre de las mismas. En todos estos casos y circunstancias, se observan muchas similitudes entre los comportamientos sindicales de dichas empresas y los de los del astillero de Puerto Real. Así, las medidas de presión colectiva de los trabajadores se concretaron en acciones tales como cortes del tráfico y del ferrocarril, manifestaciones multitudinarias 
con participación de la población de la zona o movilizaciones radicalizadas, es decir, en prácticas sindicales que, según Pizzorno (1991), son típicas del intercambio político y, por tanto, ajenas a la habitual lógica de intercambio de la negociación colectiva.

Resumiendo. Aunque el tipo de propiedad sea un rasgo que "contamina" políticamente toda clase de intercambio laboral en las empresas públicas, no es menos cierto que, tal y como hemos mostrado, en ellas las prácticas sindicales dirigidas expresamente al intercambio político se ven favorecidas por tres circunstacias particulares: $a$ ) la existencia de situaciones y contenidos reivindicativos extremos (como la reducción del empleo o, incluso, el cierre total de una empresa); b) la (cuasi)imposibilidad de presionar mediante acciones colectivas de simple presión económica (como las huelgas pacíficas), y $c$ ) la posibilidad de organizar acciones colectivas de fuerte calado político (como la alteración del orden o la orientación del voto en una u otra dirección partidista) ${ }^{18}$. La presencia de estas tres circunstancias en una empresa privada abre el camino a estrategias sindicales de intercambio político.

En consecuencia, consideramos que el planteamiento teórico y la estrategia analítica que hemos utilizado en el análisis y en la interpretación de la acción sindical en una empresa pública como el astillero de Puerto Real son aplicables también a la acción sindical en las empresas privadas en todos aquellos casos en los que la conflictividad laboral pueda tener una incidencia en el orden político.

\section{Referencias bibliográficas}

Alas-Pumariño, A. (1993). Conflictividad laboral y reestructuración industrial: El caso de Reinosa. Tesis doctoral. Universidad Complutense de Madrid. Facultad de Ciencias Políticas y Sociología.

Batstone, E.; Ferner, A. y Terry, M. (1984). Relaciones industriales y estrategias de gestión en las empresas públicas de comunicaciones. Madrid: Ministerio de Trabajo y Seguridad Social, 1990.

Castilla, P. (2007). Matagorda. Mito y esperanza. Cádiz. Edición del autor.

Crouch, C. (1982). Trade Unions: The Logic of Collective Action. Glasgow: Fontana Paperbacks.

Cuervo, A. (1985). «La empresa pública en España. Comentarios ante su reforma». Economía Industrial, 241, 33-48.

18. Tal como se ha argumentado a lo largo del artículo, esta posibilidad está muy vinculada con la relevancia económica que puedan tener las empresas sometidas a la amenaza de cierre (o reducción de su plantilla) en el ámbito local. Los casos citados — Santana Motor, Samsung y Delphi- constituyen buenos ejemplos de ello. Este no es, sin embargo, el único factor que puede explicar la capacidad de los sindicatos para obtener el apoyo de la población de la zona: la existencia de vínculos identitarios y afectivos entre una empresa o una actividad económica determinadas y la comunidad circundante es otro elemento fundamental que contribuye a explicar el éxito de este tipo de estrategias sindicales de movilización y, por tanto, condiciona el poder de negociación de estas organizaciones en el mercado político. En Pérez de Guzmán (2011) se realiza un análisis de este último aspecto. 
Cuervo, A. (1986). "La privatización de la empresa pública: la nueva desamortización». Papeles de Economía Española, 27, 331-364.

- (1992). "La empresa pública en el contexto europeo», ponencia del congreso La empresa española de la nueva Europa. Jerez de la Frontera, 20 a 22 de septiembre.

- (1997a). «Las privatizaciones en España». Cuadernos de Información Económica, 119, 10-23.

- (1997b). La privatización de la empresa pública. Madrid: Encuentros.

Ferner, A. (1985). «Political Constraints and Management Strategies: The Case of Working Practices in British Rail». British Journal of Industrial Relations, 23 (1), 47-70.

- (1986). «Relaciones laborales y dinámica social en los ferrocarriles españoles y británicos». Boletín de Documentación de la Fundación de los Ferrocarriles Españoles, 3-4, 23-59.

- (1987a). «Industrial Relations and the Mesopolitics of the Public Enterprise: The Transmission of State Objectives in the Spanish National Railways». British Journal of Industrial Relations, 25 (1), 49-75.

- (1987b). "Public Enterprise and the Politics of "commercialism": Changing Industrial Relations in British and Spanish Railways». Work, Employment \& Society, 1 (2), 179-203.

- (1990). El Estado y las relaciones industriales en la empresa pública: Un estudio comparado de Renfe y British Railways. Madrid: Ministerio de Trabajo y Seguridad Social, 1990.

- (1994). «The State as Employer». En: Hyman, R. y Ferner, A. New Frontiers in European Industrial Relations. Oxford: Blackwell, 52-79.

Florido, D. et al. (2009). El pueblo en la calle: Reconversión naval, sindicalismo y protesta popular en el astillero de Puerto Real. Sevilla: Fundación Centro de Estudios Andaluces.

Grant, R. (1996). Dirección estratégica: Conceptos, técnicas y aplicaciones. Madrid: Civitas.

Lehmbruch, G. (1977). «Liberal Corporatism and Party Government». Comparative Political Studies, 10, 91-126.

Miguélez, F. (1985). «Corporatismo y relaciones laborales en Europa en tiempo de crisis». Revista Española de Investigaciones Sociológicas, 30, 149-178.

Pendleton, A. (1988). «Markets or Politics?: The Determinants of Labour Relations in a Nationalized Industry». Public Administration, 66, 279-296.

- (1991a). «Integration and Dealignment in Public Enterprise Industrial Relations: A Study of British Rail». British Journal of Industrial Relations, 29 (3), 411-426.

- (1991b). "The barriers to flexibility: flexible rostering on the railways». Work, Employment and Society, 5, 241-257.

- (1994). «Structural Reorganization and Labour Management in Public Enterprise: a Study of British Rail». Journal of Management Studies, 31, 33-54.

- (1997a). "The Evolution of Industrial Relations in UK Nationalized Industries». British Journal of Industrial Relations, 35 (2), 145-172.

- (1997b). "What impact privatization had on pay and employment?: A review of UK experience». Industrial Relations, 52.

Pérez de GuZMán, S. (2011). "La representación social de una actividad productiva como contexto y apoyo de la acción sindical: Los astilleros gaditanos en las coplas del carnaval». Cuadernos de Relaciones Laborales, 29 (1) (enero-junio), 201-225. 
Pizzorno, A. (1978). «Intercambio político e identidad colectiva en el conflicto laboral». En: Crouch, C. y Pizzorno, A. El resurgimiento del conflicto de clases en Europa Occidental a partir de 1968. Madrid: Ministerio de Trabajo y Seguridad Social, 1991, II, 381-407.

Regini, M. (1981). "La crisis de representatividad de los sindicatos de clase». Sociología del Trabajo, 6, 51-67.

- (1991). «Las condiciones para el intercambio político: Ascenso y decadencia en la concertación en Italia y Gran Bretaña». En: Goldthorpe, J.H. (comp.). Orden y conflicto en el capitalismo contemporáneo: Estudios sobre economía política en los países de Europa Occidental. Madrid: Ministerio de Trabajo y Seguridad Social, 181-206.

- (1997). «Still engaging in Corporatism? Recent Italian Experience in Comparative Perspective». European Journal of Industrial Relations, 3 (3), 259-278.

- (2000). «Dallo scambio politico ai nuovi patti sociali». En: Della Porta, D.; Greco, M. y Szacolczai, A. (eds.). Identitá, riconoscimento, scambio: Saggi in onore di Alessandro Pizzorno. Roma-Bari: Laterza.

Schmitter, P. (1974). "Still the Century of Corporatism?». The Review of Politics, 36 (1), 85-131.

Vega, R. (1996). Crisis industrial y conflicto social. Gijón 1975-1995. Gijón: Trea. 